\title{
The role of genre-based community music: a study of two UK ensembles.
}

\section{Keywords}

Community music, orchestra, jazz, big band, reggae, wellbeing, BME communities, social inclusion.

\begin{abstract}
Background. There is a growing trend towards addressing social inclusion through community music, and at the same time, increasing interest in the way that participatory music can benefit health and wellbeing. However, relatively little research has been undertaken on community ensembles that address personal and social wellbeing through genre based music. This pilot study examined community music impacts and processes in contexts where there are higher than average health needs and wellbeing inequalities.
\end{abstract}

Methods. Participant observation and semi structured interviews were undertaken with music leaders, project managers and musicians in two UK ensembles: a community orchestra that focuses on reggae and a jazz big band. Thematic analysis identified 12 key themes.

Findings. While each ensemble addresses specific needs, common themes and challenges were identified. These include positive and negative experiences that are mediated by musical identity and genre, inclusive practices, the role of the MD, community connections, and governance and structure.

Conclusions. Membership of a community ensemble can afford creative and educational opportunities as well as supporting the wellbeing of members and a wider sense of empowerment in the communities from which they are drawn.

\section{Introduction}

There is increasing evidence that music can benefit a wide range of areas including health, wellbeing and social inclusion (Clift et al., 2009; Daykin et al., 2016). While many studies have focused on group singing, instrumental music making is also of interest: it can overcome barriers of language, culture or behaviour and therefore promote communication and 1

This is an accepted manuscript of an article published by Intellect in the International Journal of Community Music, available online at http://kacol.library.ingentaconnect.com/content/intellect/ijcm. It is not the copy of record. Copyright (C) 2018, Intellect. 
cooperation (Blacking, 1995; Fritz et al., 2009; Jindal-Snape et al., 2014). This notion of music as a societal conduit gave rise to Higgins' observation regarding music as having measurable impact in communities, rather than something that simply occurs (Higgins, 2012).

Whilst new opportunities for community music practices have been created in many countries, little attention has been directed at the impact of participatory music making by community orchestras and bands upon health and wellbeing, or upon the underlying processes that shape these impacts. Understanding the challenges faced by community music projects can help support sustainability as well as inform understanding of health and wellbeing in community settings.

To address this gap in knowledge, the following paper discusses the results of a scoping study that examined the personal and social impacts of participatory music making in contexts where there are higher than average health needs arising from documented social inequalities. The study focused on two relatively large, instrumentally based ensembles focused on popular genres (reggae and jazz) rather than classical repertoire. Both groups are known for engaging musicians from diverse backgrounds and for their inclusive work with disadvantaged communities, including refugees. Data are drawn from interviews and observations undertaken by a researcher who is unconnected with the projects (author 1). The scoping study involves an element of reflective practice (Finlay \& Gough, 2003; Finlay, 2008), the second author being the Music Director (MD) of one of the ensembles.

\section{Background}

Traditional conceptions of orchestras most comfortably align with what Higgins (2012) refers to as 'the upper levels of involvement' (p.68), with a focus on public performance by paid professionals. This notion of the orchestra as a hierarchical organisation, focused on classical music to the exclusion of musical traditions of cultural value to local communities, has been challenged on educational grounds (Baker, 2007) and on grounds of social inclusion, since the musical scene is often presented through a dominant cultural lens that may preclude the voices of under-represented groups and overlook the talents and needs of marginalised communities (Albert, 2006).

\section{2}

This is an accepted manuscript of an article published by Intellect in the International Journal of Community Music, available online at http://kacol.library.ingentaconnect.com/content/intellect/ijcm. It is not the copy of record. Copyright (C) 2018, Intellect. 
Some mainstream orchestras seek to address inclusion issues through outreach and community work in a wide variety of settings including schools, hospitals, supermarkets, hospices, prisons and factories (Ramnarine, 2011; Jindal-Snape, 2014). Although by no means universal, such activities embrace an extended notion of civic responsibility (Kahn, 2014) and help to redefine music-making as 'a pro-active, important component of lifelong learning[...]' (Shansky \& College 2010:2). Going beyond the notion of outreach, community ensembles involve and are often led by amateur musicians, with an explicit emphasis on enjoyment and social inclusion. Community orchestras can offer extended opportunities for cultural expression and can therefore promote diversity and transformation (Higgins, 2012). By moving away from traditional classical repertoire to include broader musical programmes, community musicians are continuing a connective practice that reaches out to more diverse population groups including previously underserved members of society (Veblan, 2007; Kahn, 2014).

A well-known exemplar of 'social action for music' is the Venezuelan El Sistema programme founded by the educator, musician and activist José Antonio Abreu (Wilson, 2013:11). The programme was established to offer regular musical training to the poorest children, promoting opportunities and social transformation (Wilson, 2013). However, current political and economic conditions have affected the ability of El Sistema to offer Venezuela's most vulnerable children a way out of their impoverished lives. Further, changing expectations and the introduction of a greater degree of selection as the orchestra has become internationally successful has affected the orchestra's reputation (Baker, 2014) demonstrating the difficulty of maintaining inclusivity as an orchestra grows.

As well as issues of inclusion and social transformation, there is growing interest in the effects of music making on health and wellbeing. Wellbeing benefits do not necessarily arise from processes of identity formation in professional music contexts and performance practices (Boyce Tillman, 2000; Daykin, 2005; Dolan and Testoni, 2016). Yet it has been suggested that community orchestras can contribute to the collective vitality and health of populations through sharing the joy of music making (Kahn, 2014). Most studies of music and wellbeing have focused either on community singing or on music interventions in institutional contexts. A recent review found substantial evidence that music activities can enhance Community Music, available online at http://kacol.library.ingentaconnect.com/content/intellect/ijcm. It is not the copy of record. Copyright (c) 2018, Intellect. 
wellbeing, reducing depression and anxiety while promoting positive moods in adults of all ages, including those from marginalised communities (Daykin et al. 2016). Qualitative research suggests that participants in music projects value their participation, which can provide meaning and purpose, supporting positive reworkings of identity for people in challenging circumstances (Daykin, in process; Baker \& Ballantyne, 2013; Creech et al. 2014; Dabback, 2008; Henley et al. 2012; Daykin et al. 2013; Bailey \& Davidson, 2002; Judd \& Pooley, 2014, Joseph \& Southcott, 2014; Lally, 2009; Li \& Southcott, 2012; Perkins \& Williamon, 2013; Skingley et al. 2015).

Much of this research focuses on community singing, with less emphasis on instrumental music making. However, a few studies of band membership and playing musical instruments have found similar themes of personal identity, sense of purpose and enhanced social connectivity (Dabback, 2008). These themes have been found in research on playing musical instruments in challenging settings such as prisons (Henley et al. 2012), and with adults who have no previous experience of music making (Perkins \& Williamon 2013). While there are likely to be different challenges for different ensemble types, there are also likely to be some similarities in the impacts and challenges faced by these projects. One that is well documented in community choirs is recruitment and retention, with a tendency in these groups towards recruiting participants to community choirs who are female, white and relatively well educated (Cohen, 2006; Coulton et al. 2015). Hence a key difficulty is recruiting from sub-groups who are at greater risk of poor wellbeing (Daykin et al. 2016). As Jindal-Snape (2014) suggests:

... community arts programmes are no quick-fix to social exclusion and poverty, and $[\ldots]$ may even increase the risk of reinforcing or widening social inequalities if the benefits accrue disproportionately to those who already enjoy relatively high levels of economic, social and cultural capital (Jindal-Snape, 2014:715).

While there is little research on the workings of adult community orchestras, challenges of recruitment and retention have been examined in relation to community youth orchestras, linking these with a range of factors including educational experiences, attitudes and beliefs about music, family musical background, teacher personality and teaching style, (Brandstrom 4 This is an accepted manuscript of an article published by Intellect in the International Journal of Community Music, available online at http://kacol.library.ingentaconnect.com/content/intellect/ijcm. It is not the copy of record. Copyright (C 2018, Intellect. 
\& Wiklund, 1996; Klinedinst, 1991). Access issues, such as the costs of instruments, are likely to be an issue, and ethnicity and social inequalities have been implicated. For example, where members of minority groups are underrepresented amongst music teachers, this can act as a deterrent to potential musicians from minority cultures (Albert, 2006).

Another challenge for community ensembles is that of leadership. According to Veblan (2007), community music grows largely from the competencies and ambitions of those taking part rather than teachers or leaders. However, the role of music leaders can be critical in mediating musical affordances (Daykin, in press). Historically, conductors exert considerable authority, shaping the music according to personal and cultural expectations and norms (Vredenburgh \& He, 2003). Conductors are in a strong position to champion alternative repertoire that promotes diversity and engages people who are marginalized because of age, gender, ethnicity and health status. Further, some orchestras have embraced more collaborative notions of leadership, with rotating roles and layered, self-managing teams to ensure collaboration, effectiveness and commitment (Vredeburgh \& He, 2003). Potentially, community orchestras can contribute to social justice, being infused with the ethics of care, informed by an understanding of the specific challenges faced by the communities they serve and committed to the affirmation and enablement of members and striving for the transformation of everyday life. Conductors and directors of community orchestras and bands are in an influential position to coproduce with their members and supporters to extend human values including wellbeing, fulfillment and happiness (Dewey, 1934). Realization of these ambitions may rely on a degree of formalization as ad hoc groups merge into settled structures such as community groups and charities represented by a board of directors (Carruthers, 2005).

Successfully addressing these challenges requires skills and approaches that are not necessarily taught in traditional music education. There is currently a gap in support and development for community music leaders, with a general lack of educational opportunities and recognition (Higgins, 2012). The education and development needs of community music leaders encompass not just music making strategies but broader topics such as programme evaluation and research (Higgins, 2012) as well as inclusive practice to ensure positive experiences for participants and promote wellbeing (Elliot, 2012; Daykin, in press).

5

This is an accepted manuscript of an article published by Intellect in the International Journal of Community Music, available online at http://kacol.library.ingentaconnect.com/content/intellect/ijcm. It is not the copy of record. Copyright (c) 2018, Intellect. 
A primary motivation for joining a community orchestra is the enjoyment and social interaction afforded through membership and the sense of identity and ownership derived by being part of a team (Olson, 2005). Community orchestras are recognized as a valuable context for enabling peer acceptance, group achievement and creativity (Coffman, 2002; Shansky \& College, 2010). In this sense, the community orchestra is a potential conduit for addressing social disadvantages, including wellbeing inequalities, and promoting the wellbeing and inclusion of its members and the communities from which they are drawn.

\section{Research aim}

The aim of the current study was to explore the wellbeing impacts and the sustainability issues surrounding delivery of two selected inclusive community music projects. The study was funded by the University of Winchester Centre for Arts as Wellbeing and fits within the centre's broad, developing research programme focused on the benefits and challenges of instrumental music making.

\section{Research questions}

The study sought to explore two overarching questions:

1. What are the benefits and challenges of taking part in a community instrumental music project?

2. What key sustainability issues do community music projects need to address?

\section{Research Approach and Methods}

The study is intended as the precursor to a larger project. Data collection and analysis was undertaken by the lead author. Although the second author did not directly access primary data, she drew on her extensive research on music, health and wellbeing as well as her personal experience as an orchestra leader to provide feedback on emergent themes. This was a reflexive commentary in that it informed ongoing practice and research rather than being simply reflective in the sense of solitary introspection and discussion (Finlay, 2008).

6

This is an accepted manuscript of an article published by Intellect in the International Journal of Community Music, available online at http://kacol.library.ingentaconnect.com/content/intellect/ijcm. It is not the copy of record. Copyright (C) 2018, Intellect. 


\section{The Ensembles}

The two case studies are a Community Orchestra (CO) and a Big Band (BB) that provide inclusive music making activities for people living in disadvantaged areas in UK cities. Both projects are community ensembles that focus on genre music (respectively, reggae and jazz) and strive to celebrate the contributions of members of Black and minority ethnic (BME) musicians and composers. The two groups each include between 35 and 40 male and female members drawn from diverse cultural backgrounds. They are funded from a combination of project grants, performances fees, charity fundraising activities and subscriptions from members, which are applied flexibly. Both groups rehearse regularly at a local venue and they perform regularly in their respective cities and beyond.

Neither group utilises auditions, although an assessment of participants' playing experience is made and both groups provide workshops and coaching for members. Participants are encouraged to become familiar with the musical repertoire before joining in with performances. Each group is led by a paid MD who has specialist music qualifications and broad experience, undertaking the role recognised in many traditional orchestras of arranging musical scores and conducting the musicians during rehearsals and performances. Given the varied experiences and skills of the members, the MDs assume the additional responsibility of tutoring some musicians on a more intimate, and sometimes a one-to-one level during general practise sessions. During performances, whilst the musical directors conduct, they also move to the beat of the music, standing down from the podium when soloists perform such that the orchestras' ethos of growth and equality take central stage.

There are some differences between the groups: $\mathrm{CO}$ involves adults over the age of 18 whereas BB includes adults and children from the age of 11 upwards. While both groups enjoy connections with local cultural and educational organisations, in the case of BB these links are more formalised. $\mathrm{CO}$ is a community group run by a volunteer committee while $\mathrm{BB}$ is a charity governed by a Board of eight directors whose role is to shape the strategic direction of the ensemble and make decisions that secure and protect not only the vision of the group but also its future. Board members are selected for their relevant skills and include a financier as well as representatives of orchestra members. The membership of CO has shifted in response to demographic changes in the community where it is based, with a small number 7

This is an accepted manuscript of an article published by Intellect in the International Journal of Community Music, available online at http://kacol.library.ingentaconnect.com/content/intellect/ijcm. It is not the copy of record. Copyright (C) 2018, Intellect. 
of members drawn from migrant and refugee communities. The orchestra repertoire reflects this, with world influences as well as music from its primary genre.

$\mathrm{CO}$ refers to itself as an orchestra, and it is an important part of its identity to distinguish itself from a band. Its repertoire encompasses musical influences such as reggae, ska and jazz as well as classical music. There are arrangements of well-known musicians such as Bob Marley, with improvisation incorporated, and a substantial contribution derives from local composers such that the ethnic diversity of the orchestra is reflected in the music performed. This eclectic mix is mirrored in the instrumentation, with the $\mathrm{CO}$ utilising an array of instruments including drums, guitars, keyboards and saxophones as well as traditional symphonic instruments such as woodwinds, brass and strings. BB is constituted as a traditional big band and plays standard jazz and swing repertoire.

\section{Data collection}

The lead author undertook interviews with five participants (music leaders, project managers and musicians) from each ensemble, each lasting 30-60 minutes. In addition, the researcher observed a rehearsal and a performance of each group, and conducted informal conversations with members of the audience before and after the performances. No personal information about participants was recorded: data have been anonymized in reporting. To minimize sensitivity the focus of attention was upon the ensemble as an entity rather than on individuals.

Interview data were audio recorded and transcribed in full, and thematic analysis was used to identify key themes (Braun \& Clarke 2006). Favourable ethical opinion for the study was received from the University of Winchester Ethics Committee.

\section{Findings from the interviews}

Thematic analysis identified 12 key themes, grouped in four areas as follows:

\section{Orchestra/ensemble framework, values and practices}

a) Identity and values

b) Framework and practices

8

This is an accepted manuscript of an article published by Intellect in the International Journal of Community Music, available online at http://kacol.library.ingentaconnect.com/content/intellect/ijcm. It is not the copy of record. Copyright (C) 2018, Intellect. 
c) Workshops and mentoring

\section{Skills and challenges for music leaders}
a) Main challenges for Musical Directors
b) Balancing the different levels of expertise
c) Other Musical Director skills
d) Leadership challenges

\section{Experiences of participants}
a) Positive and negative experiences
b) Wellbeing

\section{Future vision and challenges}
a) Maintaining community values
b) Governance and sustainability

The findings are discussed below.

\section{Orchestra/ensemble framework, values and practices}

\section{1 a). Identity and values}

CO was established eight years prior to the study when the project manager, who ran programmes at a local community education facility, was approached by a local musician who suggested that the community needed an orchestra that played the kind of music that was meaningful to people in the locality, many of whom were from Afro-Caribbean heritage. A network of education and music professionals worked to set up an orchestra with the goal of engaging musicians from BME backgrounds and celebrating the contribution of music from Black and diasporic cultures to the city. They searched local connections to identify a suitable MD with appropriate musical skills and community connections:

'They [Musical Director] seems to have an ear to the ground about what else is going on for people who might be part of the orchestra'

The starting point for BB was to celebrate the music and legacy of a well-known musician who came to the United Kingdom from Jamaica and found himself denied access to areas of music. BB seeks to engage people who would not normally access the arts. BB is located in a 9 This is an accepted manuscript of an article published by Intellect in the International Journal of Community Music, available online at http://kacol.library.ingentaconnect.com/content/intellect/ijcm. It is not the copy of record. Copyright (C) 2018, Intellect. 
city where there is a music Conservatoire with progressive programmes not just focused on western classical music. BB is connected with the Conservatoire, where the MD studied, and as well as amateur musicians the orchestra recruits new members from musicians graduating from the Conservatoire who are keen to establish themselves in local bands and orchestras.

Diversity is key to both ensembles and they consciously work to engage musicians from their target communities, which include people from BME communities who are underrepresented in mainstream educational organisations such as Conservatoires. While both groups currently have MDs who are white, they work extensively with role models from BME backgrounds, these are established musicians who regularly perform with the groups and offer workshops for members as well as artistic advice.

One challenge relating to diversity is the need to respect that some people might feel a sense of ownership over genre music, at the same time as introducing innovation and widening appreciation of that genre. In $\mathrm{CO}$, for which creating and performing original music is a key aim, this is addressed by sensitive negotiation with members and stakeholders, as well as careful attribution and recognition of contributors. Another challenge is how to encourage musicians from a broad range of backgrounds to take part. Both ensembles operate in areas of their respective cities that some members of the wider community are reluctant to venture into, having been negatively portrayed in the media in the past.

\section{1 b). Framework and practices}

Framework and practice issues include recruitment and retention of members, performance practices and income generation.

Regarding recruitment, the long-term engagement of a group of core members of musicians has provided essential continuity and supports recruitment. These members offer musical suggestions to the MD and provide considerable peer support, keeping an eye on less experienced players who might occasionally be lost in the score, and encouraging them to take solos. A great deal of camaraderie is evident at rehearsals, through the praise given to soloists, the general exchange of information that may prove helpful and the notable 
bonhomie. The MDs model orchestra values by being friendly and amenable working as a team, seeking and accepting suggestions from members.

Both groups use outreach strategies, such as projects and performances with local schools, to publicize what they are doing and, in the case of BB, recruit young members. The main difference between the two groups is that BB enjoys more formal connections with the local music service and the Conservatoire while $\mathrm{CO}$ relies on grass roots connections within the community and local and national music genre connections.

A key challenge is recruiting musicians with diverse skills and musical backgrounds. One of the key early achievements of $\mathrm{CO}$ was to recruit musicians who are well respected within the local community. This continues to be addressed by involving local people in organisational development and commissioning musical works from local composers. Effective marketing and publicity, including word of mouth sharing of information, is also an important means of recruitment.

Both ensembles experience fluctuations in membership, indeed, one MD noted that attendance is strong when performances are looming. Another key challenge is maintaining the right balance of instruments and performers. Adult learners seem drawn to instruments that can contribute to an imbalance: both groups have at times been over supplied with saxophones while $\mathrm{CO}$ often finds itself short of brass and string players. However, in practice new members are welcomed and a space made for them, regardless of instrument. CO has encountered a challenge that, within the local area, BME musicians who come forward seem more likely to play instruments such as drums and guitars, being underrepresented in some instrumental groupings, particularly brass and strings. As a response, $\mathrm{CO}$ has sought to establish connections with local and national programmes that train and develop instrumental skills in young musicians from BME backgrounds.

Both groups have a balance of male and female members across a wide age range. Neither ensemble has a formal policy on disability, although instances were observed where health problems and impairments were accommodated and supported. For example, seating and equipment are arranged to suit the needs of participants with mobility and visual impairments. Community Music, available online at http://kacol.library.ingentaconnect.com/content/intellect/ijcm. It is not the copy of record. Copyright (c) 2018, Intellect. 
Both groups recognise the importance of regular performances, and both groups need to adapt to a variety of performance situations and venues. BB enjoys the benefit of a regular residency in the city's concert hall, an imposing building with double rotating doors leading to a large foyer and then to the performance area. This residency attracts a regular audience of devoted followers who are loyal both to the orchestra and the venue. This formal setting provides excellent views and acoustics. The MD introduces the songs with an informative summary as to the historical or musical roots. The seated audience listen attentively, although some of the musicians would like it if there was an opportunity to dance.

CO does not have a regular performance venue, but the researcher attended an open access celebration performance that they gave in a leading local venue. This was an accessible concert hall located near several bars and it attracted a large audience, including many passers-by who joined upon hearing music. The informal atmosphere created an air of festivity, possibly enhanced by the younger age audience demographic. There were some notable performance challenges, including a lack of seating meant that audience members found it difficult to see and hear. Different orchestra members and vocalists introduced each piece of music and gave charismatic performances, sometimes dancing across the stage, clapping and encouraging the audience to join in. This energized approach animated the crowd.

For the ensembles, performances are an important source of income. One MD pointed out that charging a professional fee reflects the orchestra's worth and sends a more general message that music should be valued. Both ensembles adopt flexible practices in relation to the payment of subscriptions.

'I like the fact that we, at the moment are inclusive at a level where you pay what you can to be part of it'.

Both orchestras receive grant funding, and whilst grant monies are extremely helpful to the ensembles, managing these brings responsibilities that can be onerous for a small group, such as monitoring and reporting and fulfilling the requirements of funders.

\section{1c). Workshops and mentoring}

12

This is an accepted manuscript of an article published by Intellect in the International Journal of Community Music, available online at http://kacol.library.ingentaconnect.com/content/intellect/ijcm. It is not the copy of record. Copyright (C) 2018, Intellect. 
Providing regular educational workshops helps to develop the skills of existing members as well as attract new ones. Both groups offer regular workshops led by professional music leaders covering topics such as repertoire, technical skills, music theory and performance. As well as promoting learning the workshops and build relationships between the orchestra and the wider music world. One MD occasionally runs ad hoc workshops during rehearsals when a musical challenge becomes apparent.

Generally, workshops were evaluated by participants with enthusiasm: participants appreciate the opportunity to learn, gain a broader understanding of music and connect with accomplished, sometimes well-known musicians. For the MDs, workshops are important for driving up performance standards and confidence. Workshops also present several challenges, one of which is pitching the material at the right educational level. If the level of difficulty is too high or too low it can alienate and discourage participants, as one member explained:

'You think, 'Oh, I'm no good'. Where the ones that had been really inclusive of everybody's different ability there was an overpowering feeling of 'This has been a great workshop, and we want more [...]'.

Another challenge is to ensure that the authenticity of workshop leaders is recognized:

'Any time you've got someone external coming in, especially with our lot, if you don't have an obvious understanding of (genre), then there may be some people who disengage'.

\section{Challenges and skills of music leaders}

\section{$\underline{\text { 2a). Main challenges for Musical Directors }}$}

A key challenge for the orchestras is gaining the trust of musicians who may, for various reasons, be sceptical about involvement in a formal music group.

'You have to nurture people to come and perform, to come and share their music, to trust that you're not going to steal their music.'

The MDs seek to valuing the skills and experiences of participants, including those who may be unfamiliar with formal music making. At the inaugural rehearsal of $\mathrm{CO}$, the MD devised a 13

This is an accepted manuscript of an article published by Intellect in the International Journal of Community Music, available online at http://kacol.library.ingentaconnect.com/content/intellect/ijcm. It is not the copy of record. Copyright @ 2018, Intellect. 
genre quiz based on listening to the bass lines of well-known repertoire and naming the song, its performers and its composer. With no reference to notation, this served to level the playing field and reduce hierarchies at the outset, for example between those who read music and those who do not.

For both MDs, there is recognition of the need to set and manage appropriate expectations. While wishing to encourage participants to achieve a high standard of performance, both are aware that sometimes ambitions need to be contained. For example, one MD, having unsuccessfully attempted to correct a fault, decided to modify the requirements of the performance rather than knock the musicians' confidence. They also encourage a sense of inclusion and ownership by passing decision-making as to how particular pieces should be performed to the musicians.

Occasionally conflicts, disagreements and disappointments arise within the groups, around issues such as choice of repertoire, music programming, featuring of soloists, workshop topics and selection of music mentors and collaborators. Both MDs recognise that careful negotiation is sometimes needed to resolve challenges. Participants commented on the MD's authenticity and sincerity as well as their open approach.

'[The Musical Director] is trying to make sure that everybody who wants to have a say, and you'll see that in the rehearsal tonight hopefully, is allowed to have a voice. It's [the orchestra] a true cooperative, a true sense of community and working together, where everyone has a voice.'

\section{$\underline{\mathbf{2 b}) \text {. Balancing the different levels of expertise }}$}

Both orchestras include members with different musical experiences, ranging from near beginners to semi-professionals and music graduates. A key challenge therefore is balancing different musical skills and experiences to ensure that everyone can be included, whilst providing meaningful challenges and inspiring all participants. This requires careful management. Both MDs are careful to select and create meaningful repertoire that can be performed by people with different levels of skill. They carefully craft and modify scores and resources to ensure that all could take part on an equal footing. Another approach is to elicit, 
develop and harness the creativity of members to create effective performances, which is achieved by encouraging experimentation and growth. Both MDs encourage members to improvise and ensure that everyone has an opportunity to take a solo, even though this can take up considerable time in rehearsals.

\section{$\underline{\text { 2c). Other Musical Director skills }}$}

As well as demonstrating musical skills, the MDs seem open, being willing to share decision making, patient, sensitive and committed to their groups. The MDs were observed to demonstrate inclusivity and a non-judgemental stance, for example, when responding to a musician who was struggling with a phrase, the MD spent time with them, offering support and encouragement.

While being inclusive and non-judgemental, the MDs at times need to assert control without causing offence, and this requires diplomacy. The researcher noted that musicians frequently talk over the MDs during rehearsals. Sometimes camaraderie spills over into general talking and distraction. The general noise level, from chatter and solo instrumental practice, seems to rise the moment the MD attends to a query from an individual member. Attempts by members to quieten the chatter by asking others to stop talking are generally ineffectual. When an authoritative tone was taken by a MD firmly but fairly telling participants when and where mistakes had been made, this was generally welcomed by participants.

\section{$\underline{\text { 2d). Leadership challenges }}$}

Both orchestras require systems for ensuring effective and sustainable music leadership. For example, it is essential that each group has contingency plans as to who will lead rehearsals and performances should the conductor be absent. BB, being longer established, has several ex-conductors on whom they can rely. It is important that these music leaders have knowledge about the group and its members:

'Normally we go back to ex-conductors [...] they're the kind of people who may be the first call because they know what the band's about. It's quite rare for someone to be asked to run the rehearsal that's never been involved in the band.' 
In the event of no ex-conductors being available, the orchestra looked to their own resources, calling upon the talents of existing members.

'I think, on some occasions, they've [the orchestra members] actually run it [rehearsal] themselves, sort of nominated one member of the band to run a rehearsal just for one week'.

Given the musicians' diverse abilities, different characters, and musical challenges, drawing upon internal talent is a useful strategy. In the case of $\mathrm{CO}$, filling the breach in the MD's absence is usually undertaken by a member of the orchestra.

'They'd bring something different, a fresh perspective [...] it might be that they have a particular impression of a piece'

Additionally, the opportunity to lead the orchestra offers musicians the chance to develop their skills and confidence. According to one member, the leaders were respected equally, irrespective of whether or not they were professionals.

'Where one of the orchestra members has volunteered, there's been a positive reception [...] whether it's for their own professional music work, or if they're not professional musicians, it's giving them confidence of having a new skill or developing a new skill.'

Both MDs were aware of diversity issues in relation to their own backgrounds, being white, highly educated individuals. They were observed to engage reflexively with the topic of diversity, acknowledging the challenges and adopting several strategies to address equality issues. Both MDs actively seek to ensure that the groups are exposed to musical mentoring by strong male and female role models drawn from diverse ethnic backgrounds. Both demonstrate a commitment to participatory leadership and shared decision making, engaging orchestra members in thinking about how the music can be improved. Both MDs recognise the importance of sharing musical leadership roles, working collaboratively and reaching out to established local and national artists and creative advisors from BME backgrounds.

\section{Participants' experiences}

\section{$\underline{\text { 3a). Positive and challenging experiences }}$}


Being a member of a community orchestra involves both positive and challenging experiences. All the interviewees described positive experiences from their membership including feelings of pride, not just in their own achievements but for what they may have brought to their community.

'Yes, really proud. Really excited to be part of something and to have perhaps introduced people to something they wouldn't have thought existed in [the city]'.

One interviewee referred to music as 'an international language', capable of breaking down barriers, whereby benefitting society. Another recalled the powerful effect of a performance:

'[...] ]everybody just got up in the audience. They were dancing in the aisle[...]It was like electricity went across the whole place'.

Both orchestras seem to generate a strong sense of unity, despite the diverse backgrounds of participants.

'When we get together we work all as one unit. We might not always play like one unit, but together, we all seem to gel; even though we're all from different backgrounds'.

'I play the guitar and I've been with the orchestra ever since it first began [...]It's like a community. It's like a little family actually'.

$\mathrm{CO}$ seems to engender musical connections and friendships between people who wouldn't ordinarily meet during their everyday lives.

There are also frustrations, such as when venues and promotors were unable to meet technical requirements and expected the groups to perform with inadequate space, lighting and sound engineering arrangements.

In addition, a downside to the bonds the musicians experienced was that when members left, those remaining must adjust to the space created and the changes that absence occasioned. Community Music, available online at http://kacol.library.ingentaconnect.com/content/intellect/ijcm. It is not the copy of record. Copyright (c) 2018, Intellect. 
'It can be a bit disappointing when a lot of people move on at the same time, so you kind of think you've got a whole group of people playing together, and then suddenly, their lives change, or whatever and they - that can feel a bit weird'

\section{3b). Wellbeing}

One of the most striking observations was the genuine pleasure, camaraderie and enjoyment that all the members seem to experience from participating in the orchestras. This was evident through the smiling and joking, and the friendships that they seemingly share, as voiced by one of the musicians,

'You're not criticized. You feel people are there for you and there's a warmth about the orchestra'

The warmth and friendship extended by orchestra members reinforced self-worth and a sense of belonging for participants. As one member noted, 'I don't think anybody would ever go and not be talked to'.

Apart from the positive emotional exchange, the orchestras fill a social niche, as one musician commented,

'If you're somebody, for example on benefits and doesn't get out much, this is a way of meeting people[...]maybe English isn't your first language and you don't know many people, or you're new to [the city], this is a way of getting to meet new people'.

One musician's narrative demonstrated how these values had been realized by her in the setting of the orchestra,

'It [joining the orchestra] made me feel better inside and gave me something to work for [...] Sometimes you feel a bit down and then you go and rehearse and, by the time you come back, you're happy'.

Some musicians who have experienced mental health issues seem to find support from playing music with others in the groups. 
P: 'I'm still pretty nervous. I think that if the orchestra wasn't the way it was, I wouldn't still be playing at all, so I think it's been as supportive as it could possibly be for me.

R: How does it support you?

P: Just by being interested in me[...] that you are a valued piece of something.'

Involvement with a community orchestra can also engender difficult feelings, including boredom, frustration and performance anxiety. As well as euphoria, concerts could include disappointing moments, such as when the musicians berated themselves for a poor performance that they felt didn't correspond to the effort expended at rehearsals.

'[When things go wrong] the audience - they understood[...] but I think we gave ourselves more of a talking to than the audience gave us. We felt worse than the audience because we know what we put in'.

\section{Future vision and challenges}

\section{4a). Maintaining community values}

One participant identified a potential threat that the orchestra's increasing recognition might lead to prestigious performances that could deflect the group from its original values and aims:

'I think you can end up being - especially, really excited because you get invites, and then suddenly, you suddenly realize that you've become this thing that's really attractive to a certain audience. It's about being true to the community I think[...] So I suppose it would be really good for us to get more gigs and to get festivals or stuff like that, but it's something about how we can then use that more confidence that we've got and make sure that we're still opening our doors, like locally, in a meaningful way. Otherwise it just becomes like, the selected few who benefit. You sort of become that phenomenon because you're a diverse orchestra, and people like diverse things in my mind'.

This was offset by commitment to the community values as modelled by the MDs and the musicians in various ways. For example, both ensured that those with leadership roles regularly 19

This is an accepted manuscript of an article published by Intellect in the International Journal of Community Music, available online at http://kacol.library.ingentaconnect.com/content/intellect/ijcm. It is not the copy of record. Copyright (C 2018, Intellect. 
engaged with community organisations such as schools, charities and informal networks where community values could then be incorporated into the orchestra. This work involved teaching and learning where people from disadvantaged areas could ultimately aspire to enrolment at the local Conservatoire.

We do a lot with young people within [disadvantaged area]. There's a couple of flagship projects... one where about 300 schoolchildren come and practise and perform a newly commissioned piece each year. [...] they're really beginners, and they work with a composer and our tutors throughout the year and then they showcase it... Then we have a summer school [...] It's free to all from [disadvantaged area]. We have a good, diverse range of people for that. [...] We encourage them to stick with us for years and we've seen people go off to the Conservatoire now and then become musicians.

In addition, both ensembles commissioned works from local composers, engendered a sense of ownership and strengthening connections. The musicians were strongly aware of the unifying potential of music:

Music breaks down all barriers, anyway, in my experience. It does, it just breaks down barriers. I think it's an international language. [...] [ [...] there's this French guy who I met [...]. I'd never seen this guy before. We were having a rehearsal and [a friend] said he's got this guy who plays keyboard. I said, 'Oh yes. Bring him along,' and from then on we just became friends. We were all - a little group of us - it wasn't even my house, I invited him to somebody else's house. He just fitted in. Once the music started and everybody was... We're all musicians: we're not French, we're not Jamaican, we're not English - we're musicians.

\section{4b). Governance and sustainability}

$\mathrm{CO}$ is currently reviewing its frameworks and governance arrangements. For its first few years it relied extensively on its MD, not just for music leadership but for a wide range of functions:

'I think it [the orchestra] needs to be on a firmer financial footing. I think it needs a stronger committee group with clearer role descriptions and accountability....

20

This is an accepted manuscript of an article published by Intellect in the International Journal of Community Music, available online at http://kacol.library.ingentaconnect.com/content/intellect/ijcm. It is not the copy of record. Copyright (C) 2018, Intellect. 
Succession planning is also an issue, particularly for $\mathrm{CO}$ which operates in an area where there isn't a Conservatory that can provide future music leaders:

It needs better resourcing so that we have more music, mentors and people, so there's genuine learning and development taking place all the time...I think there needs to be a widening of the skills base .... And I think it needs to be owned by [the city] in some sort of way'.

In this study, interviewees voiced on-going commitment and a desire for the project to continue, evident through certain member's willingness to spread the joy of performing around the world:

'I'd like to be going around playing everywhere[...]I'd love that [...] next thing Musical Director says, 'Right. Go and get your passport. We're going to France, we're going to Germany[..]. I think this is something we could take to people and say, 'We can do this as well'. Forget all about the arguments of today man. Come and play some music'

\section{Discussion}

This pilot project has explored two community music ensembles in the UK, examining their impacts and challenges. There are some key differences between the orchestras, and also some important similarities. Both have a strong identity, forged through their connection to their respective music genres (reggae and jazz) as well as through their inclusive practices, workshops and mentoring, and active engagement with the community. This progresses from regular contact with community organisations, through to investment in local musicians and nurturing of young people. A key priority for such groups is ensuring that those in leadership roles are well connected with local community organisations, such as schools, music venues and organisations, charities and informal networks.

As well as creative and educational opportunities, both orchestras support the wellbeing of members. During observations the musicians seemed unmistakeably to be having a good time. The groups seemed to successfully overcome social barriers, creating a warm and welcoming space for newcomers and established members. Participants spoke of being valued and experiencing a rare sense of belonging. The orchestras offer a creative and social niche for 21

This is an accepted manuscript of an article published by Intellect in the International Journal of Community Music, available online at http://kacol.library.ingentaconnect.com/content/intellect/ijcm. It is not the copy of record. Copyright (C) 2018, Intellect. 
people on low incomes, people isolated in the community and people for whom English is not their first language.

These findings are aligned of findings from international research on the impact of participatory music making on wellbeing (Daykin and Bunt, 2015; Daykin et al. 2016; Baker, 2007; Carruthers, 2005; Dabback, 2008; Jindal-Snape et al., 2014; Joseph \& Southcott, 2014; Judd \& Pooley, 2014). Hence being part of a community orchestra or band can afford positive family-like experiences that seem particularly important to those who are at risk of social isolation, including older people and members of marginalised communities. At the same time, participants may experience negative feelings including boredom, anxiety about performing, self-consciousness, and negative impacts of group dynamics.

It is important to understand what mediates these positive or negative impacts. Research suggests that wellbeing is mediated by a complex mix of individual, contextual and social factors, including the characteristics of individual members, educational experiences, formal and informal musical knowledge and skill, as well as attitudes and beliefs about music that are fluid and shaped by specific contexts, societal discourses and relationships (Daykin 2012; 2017). This study reinforces the suggestion by Judd and Pooley (2014) regarding the mediating role of ensemble ethos, organisation, repertoire and programming, and the skills and qualities of the MD (Judd \& Pooley (2014).

The identity of the MD is symbolically important. Historically, the privileged status of the symphony orchestra has been underlined by patronage by the social elite and their influence over the exchange of cultural capital, implicating conductors by default in preserving exclusivity (Ponchione, 2013). In this study, the MDs are invested both professionally and personally in the orchestras, often advocating for them, responding to opportunities and connecting the orchestra through their professional networks. However, in this study, the symbolic focus extends beyond the MD. Both groups benefit from the involvement of a core group of musicians who provide a stable centre around which satellite musicians rotate. These members appear to act as identity markers, offering support, information and a sense of belonging that anchors the orchestras. Nevertheless, the MD skill set is critically important. MDs of community orchestras need to demonstrate competence, artistic focus and music leadership skills, and they also need to show patience and commitment to orchestra values, Community Music, available online at http://kacol.library.ingentaconnect.com/content/intellect/ijcm. It is not the copy of record. Copyright (c) 2018, Intellect. 
balancing egalitarian values with authority to ensure that music making delivers positive experiences for participants. They also need to demonstrate awareness of the broader context in which the ensemble sits, engendering the respect and trust of musicians and members of local communities in order to ensure sustainability.

The study has illustrated the challenges that such groups can face in relation to sustainability. These include difficult questions about organisational development and fundraising, particularly as their ethos is to be flexible regarding payment of member subscriptions. Creating sustainable frameworks and governance arrangements can protect community ensembles from the waning of commitment and enthusiasm of leading individuals, which would threaten their sustainability. Regarding governance and structure, there are some key differences between the groups, notably that BB is more formally constituted and benefits from an external Board of Governors as well as more formal links with music organisations within the locality. In contrast, $\mathrm{CO}$, a younger organisation, has been relatively informally run and at times has relied on its MD for a broad range of functions. More recently, its members have agreed on the need for a more formal structure, with musical and non-musical roles and responsibilities clarified.

The second author draws on an extensive research background as well as experience of ensemble leadership, and in her reflexive commentary she refers to both to provide theoretical and personal insights into the processes and challenges of music leadership in a specific context. In turn, the research process has afforded the second author a valuable opportunity for reflection, identifying orchestra strengths and achievements and highlighting critical challenges and prerequisites for sustainability. These insights have been shared with CO members and have energised the group, informing their thinking about future options, goals and structures.

\section{Areas for future research}

This scoping study has highlighted several areas for future research. These include; the impact of different structures and organisational frameworks on the development of community music projects; the role of music directors and the effects of gender, cultural heritage and ethnicity upon the relationships between MD and musicians; and the impact of participation Community Music, available online at http://kacol.library.ingentaconnect.com/content/intellect/ijcm. It is not the copy of record. Copyright (C) 2018, Intellect. 
in community orchestras and bands (as opposed to singing) on the health and wellbeing of members.

\section{Conclusion}

This pilot study suggests that in the UK, genre based community orchestras provide more than a space where musicians can rehearse, learn and perform musical repertoires they love. The orchestras also engender connectivity, wellbeing and a sense of connection with their communities, contributing to wellbeing in the broadest sense and helping to redress cultural and representational inequalities by celebrating the talents and contribution of minority communities. The two ensembles were responsive to their communities and their characteristics would not simply transpose in different geographical areas. Nevertheless, some generalizable features of successful ensembles did emerge, including an understanding of factors that mediate wellbeing outcomes and contribute to sustainability. These include: the creation of strong identities and empowerment through connection to music genres linked with underserved communities; engaging a core group of musicians who enact the ensemble's values; an MD skill set that aspires to high level musicianship as well as an awareness of social action; reflexive engagement with questions of governance and structure; and the ability to build and sustain strong community connections.

\section{References}

Albert, D.J. (2006). Socioeconomic status and instrumental music: What does the research say about the relationship and its implications? Applications of Research in Music, 25(1), 39-45.

Bailey, B. A. and Davidson, J. W. (2002). 'Adaptive characteristics of group singing: Perceptions from members of a choir for homeless men'. Musicae Scientiae, 6 (2), pp 221-256.

Baker, G. (2014). El Sistema: A model of tyranny? The Guardian, Tuesday 11 November. Available from: https://www.theguardian.com/music/2014/nov/11/geoff-baker-el-sistemamodel-of-tyranny [Accessed]: 18 October 2017.

Baker, S., (2007). 'Young people and community radio in the northern region of Adelaide, South Australia'. Popular music and society, 30 (5), pp.575-590. Community Music, available online at http://kacol.library.ingentaconnect.com/content/intellect/ijcm. It is not the copy of record. Copyright (c) 2018, Intellect. 
Boyce-Tillman, J. (2000). Constructing musical healing: The wounds that sing. London: Jessica Kingsley Publishers.

Brandstrom, S., and Wiklund, C. (1996). The social use of music and music education. Canadian Music Educator, 37(3), 33-36.

Braun, V., and Clarke, V. (2006). 'Using thematic analysis in psychology'. Qualitative Research in Psychology, 3 (2), pp.77-101.

Carruthers, G. (2005). 'Community music and the "musical community": Beyond conventional synergies'. ([online]) International Journal of Community Music, 3, pp.1-17. http://www.intellectbooks.co.uk/MediaManager/Archive/IJCM/Volume\%20C/04\%20Carruth ers.pdf Accessed 28/03/2017.

Clift, C., Camic, Chapman, B., Clayton, G., Daykin, N., Eades, G., Parkinson, C., Secker, J., Stickley, T. and White, M. (2009). 'The State of Arts and Health in England. Arts and Health'. International Journal of Research, Policy and Practice, 1 (1), pp.6-35.

Coffman, D.D. (2013). 'Common ground for community music and music education'. International Journal of Community Music, 6 (3), pp.273-280.

Coffman, D. D. (2002). 'Music and quality of life in older adults'. Psychomusicology: A Journal of Research in Music Cognition, 18(1-2), 2002, pp.76-88.

Dabback, W. M. (2008) 'Identity formation through participation in the Rochester New Horizons Band programme'. International Journal of Community Music, 1 (2), pp.267-286.

Creech, A., Hallam, S., Varvarigou, M., Gaunt, H., McQueen, H. \& Pincas, A. (2014). The role of musical possible selves in supporting subjective wellbeing in later life. Music Education Research, 16, 32-49.

Daykin, N. (2005). Disruption, dissonance and embodiment: creativity, health and risk in music narratives. Health: An Interdisciplinary Journal for the Social Study of Health, Illness and Medicine, 9, (1), 67-87.

25

This is an accepted manuscript of an article published by Intellect in the International Journal of Community Music, available online at http://kacol.library.ingentaconnect.com/content/intellect/ijcm. It is not the copy of record. Copyright (C) 2018, Intellect. 
Daykin, N. (2012) Developing social models for music and health research: a case study of research in a mental healthcare setting. In MacDonald, R., Kreutz, G., \& Mitchell, L. (eds) Music, Health and Wellbeing. Oxford University Press

Daykin, N. (2017) Arts, Health and Wellbeing: A social inquiry. In Stickley, T. \& Clift, S. (eds) Arts, Health \& Wellbeing: A Theoretical Inquiry. Cambridge Scholars Press.

Daykin, N. (in process). Singing and wellbeing across the life course: Evidence from recent research. In Heydon, R., Fancourt, D. \& Cohen, A. Routledge Companion to Interdisciplinary Studies in Singing: Volume III Well-being. London: Routledge.

Daykin, N. \& Bunt, L. (2015). Music as a resource for health and wellbeing. I. Söderback (ed). International Handbook of Occupational Therapy Interventions. Springer

Daykin, N., de Viggiani, N., Moriarty, Y. and Pilkington, P. (2013). 'Music making for health, well-being and behaviour change in youth justice settings: a systematic review'. Health Promotion International, 28 (2), pp.197-210.

Daykin, N., Julier, G., Tomlinson, A., Meads, C., Mansfield, L., Payne, A. et al. (2016) 'Music, singing and wellbeing in health adults. A systematic review of the wellbeing outcomes of music and singing in adults and the processes by which wellbeing outcomes are achieved. What Works for Wellbeing'. ([online]). https://whatworkswellbeing.org/musicsinging/\#download Accessed 28/03/2017.

Dewey, J. (1934). Art as Experience, New York: Perigee Books, pp. 3-351.

Dolan, P. \& Testoni, S. (2016) Supporting analysis: music and singing. What Works Centre for Wellbeing. https://www.whatworkswellbeing.org/product/supporting-analysis-music-singingand-wellbeing/ Accessed 20.10.17

Elliott, D. (2012). 'Music Education as/for Artistic Citizenship'. ([online]) Music Educators Journal, 99(1), http://journals.sagepub.com/doi/full/10.1177/0027432112452999 Accessed 04/04/2017. Community Music, available online at http://kacol.library.ingentaconnect.com/content/intellect/ijcm. It is not the copy of record. Copyright (c) 2018, Intellect. 
Ernst, R. (2011). 'Music for life: An interview with Roy Ernst'. International Journal of Community Music. 4(3), pp.277-280(4).

Finlay, L. and Gough, B. (2003). Reflexivity. A practical guide for researchers in health and social sciences. Oxford: Blackwell Publishing Company.

Finlay, L. (2008). Reflecting on 'Reflective practice'. PBPL paper 52. Available from: http://www.open.ac.uk/opencetl/sites/www.open.ac.ukcetl/files/files/ecms/webcontent/Finlay-(2008)-Reflecting-on-reflective-practice-PBPL-paper-52.pdf [Accessed]: 11 May 2016.

Fritz, T., Jentschke, S., Gosselin, N., Sammler, D. and Peretz, I. (2009). 'Universal recognition of three basic emotions in music'. Current Biology, 19(7), pp.573-576.

Henley, J., Caulfield, L.S., Wilson, D. \& Wilkinson, D.J. 2012. Good Vibrations: positive change through social music-making. Music Education Research, 14(4), 499-520

Higgins, L. (2012). Community Music: In Theory and in Practice, New York: Oxford University Press, 3-221.

Jindal-Snape, D., Morris, J., Kroll, T., Scott, R., Toma, M., Levy, S., Davies, D. and Kelly, C. (2014). 'Community-based music programmes, and health and inequalities: impact on children/adolescents and their families: Systematic literature review (Work Package 3)' ([online]).

http://www.gcph.co.uk/assets/0000/4513/GCPH_Communitybased_music_and_health_Sys_R eview_WP3.pdf Accessed 10/01/2017.

Joseph, D. and Southcott, J. (2014). 'Personal, musical and social benefits of singing in a community ensemble: Three case studies in Melbourne (Australia)'. The Journal for Transdisciplinary Research in Southern Africa, 10(2), p.13.

Judd, M. \& Pooley, J.A. (2014) The psychological benefits of participating in group singing for members of the general public. Psychology of Music. 42(2)269-283. Community Music, available online at http://kacol.library.ingentaconnect.com/content/intellect/ijcm. It is not the copy of record. Copyright (c) 2018, Intellect. 
Kahn, P. (2014). 'American orchestras: Making a difference for our communities'. ([online]) http://animatingdemocracy.org/sites/default/files/Orchestras_TrendPaper.pdf Accessed $\underline{10 / 01 / 2017 .}$

Klinedinst, R. E. (1991). Predicting performance achievement and retention of fifth grade instrumental students. Journal of Research in Music Education, 39, 225-238.

Lally, E. (2009). The power to heal us with a smile and a song: Senior wellbeing, music-based participatory arts and the value of qualitative evidence. Journal of Arts \& Communities, 1(1), $25-44$.

Li, S. \& Southcott, J. 2012. A place for singing: Active music engagement by older Chinese Australians. International Journal of Community Music, 5(1), 59-78.

Olson, K. (2005). 'Music for community education and emancipatory learning'. New Directions for Adults and Continuing Education, 107, pp.55-64.

Perkins, R. \& Williamon, A. 2014. Learning to make music in older adulthood: A mixedmethods exploration of impacts on wellbeing. Psychology of Music, 42, 550-567.

Ponchione, C. (2013). Exploring a metamorphosis: Identity formation from an emerging conductor. Arts \& Humanities in Higher Education, 12(2-3) 181-193.

Ramnarine, T.K. (2011). 'Symphony Orchestras'. Ethnomusicology Forum, 20(3), pp.327-351.

Shansky, C. and College, M. (2010). 'Adult motivations in community orchestra participation: A pilot case study of the Bergen Philharmonic orchestra (New Jersey)'. Research and Issues in Music Education, 8(1), pp.2-12.

Skingley, A., Martin, A. \& Clift, S. (2015). The Contribution of Community Singing Groups to the Wellbeing of Older People. Participant Perspectives from the United Kingdom. Journal of Applied Gerontology, p.0733464815577141. Accessed 20.10.17. 
Veblan, K.K. (2007). The Tapestry: Introducing community music. In D.Elliott., S.

Messenger., Silveman, M. ed., Community music today, $1^{\text {st }}$ ed. Washington DC: R\&L

Education, pp. 1-305.

Vredenburgh, D., and He, I.Y. (2003). Leadership lessons from a conductorless orchestra.

Business Horizons, 46(5):19-24.

Wilson, K. (2013). 'The Orchestra, the Community and Cultural Value'. ([online]) Kerry

Wilson Institute of Cultural Capital . http://iccliverpool.ac.uk/wp-

content/uploads/2014/05/IHLRN-interim-report-KW-July-2013.pdf Accessed 27/06/2016.

\section{Appendix}

\section{Insert Figure 1 here}

